\title{
$\mathrm{N}$-acetyl cysteine: Is it an option for treatment of drug induced acute pancreatitis? retrospective, observational study
}

\section{N-asetil Sistein: İlaca Bağlı Akut Pankreatitte de Kullanılabilecek Bir Tedavi Seçeneği mi? Retrospektif Gözlemsel Çalışma}

\author{
Osman Bülent Zülfikar ${ }^{1}$, Halil Haldun Emiroğlu ${ }^{2}$
}

1 İstanbul Üniversitesi Cerrahpaşa Tıp Fakültesi ve Onkoloji Enstitüsü Çocuk Hematoloji-Onkoloji Bilim Dalı, İstanbul, Türkiye 2 Selçuk Üniversitesi Tıp Fakültesi Çocuk Gastroenteroloji Bilim Dalı, Konya, Türkiye

$\ddot{O Z Z}$

Amaç: İlaçlar akut pankreatit etiyolojisinin nispeten seyrek görülen bir nedenidir. Çalışmamızda ilaç kullanımına bağlı aku pankreatit gelişen ve $\mathrm{N}$-asetil sistein tedavisi sonrası iyileşen 6 hastanın retrospektif olarak değerlendirilmesi amaçlanmıștır.

Gereç ve Yöntem: 2007-2017 yılları arasında ilaca bağlı akut pankreatit tanısı alan ve $\mathrm{N}$-asetil sistein tedavisi uygulanan 6 çocuk hastanın dosyaları retrospektif olarak incelendi. Altı hastanın akut pankreatit tanısı "Uluslararası Çocuk Pankreatit Çalıșma Grubu" tarafından önerilen kriterlere göre konuldu. Hastalığın şiddet derecesi NASPGHAN kriterlerine göre belirlendi.

Bulgular: Akut pankreatit tedavisi sırasında $\mathrm{N}$-asetil sistein uygulanan ilaca bağlı akut pankreatitli 6 hastanın tümü tamamen iyileşti.

Sonuç: N-asetil sistein tedavisi, ilaca bağlı akut pankreatit tedavisi için faydalı gibi görünmektedir.

Anahtar Kelimeler: Pankreatit, N-asetil sistein

\section{ABSTRACT}

Aim: Drugs are relatively rare cause of acute pancreatitis. We aimed a retrospective evaluation of 6 patients with drug induced acute pancreatitis, who were recovered after $\mathrm{N}$-acetyl cysteine treatment.

Materials and Methods: . The information in the files of 6 patients with drug induced acute pancreatitis who were improved after $\mathrm{N}$-acetyl cysteine treatment between 2007 and 2017 was retrospectively reviewed. The criteria recommended by the International Study Group of Pediatric Pancreatitis were used for the diagnosis of acute pancreatitis in 6 patients. The severity of the disease was determined according to NASPGHAN criteria.

Results: All of the 6 patients with drug induced acute pancreatitis who underwent $\mathrm{N}$-acetyl cysteine during the treatment of acute pancreatitis were completely healed.

Conclusion: N-acetyl cysteine treatment seems to be beneficial for drug induced acute pancreatitis.

Keywords: Pancreatitis, N-acetyl cysteine 


\section{GİRIŞ}

$\mathrm{N}$-asetil sistein (NAC) mukus atılımını kolaylaştırdığı için başta akciğer hastalıklarının tedavisinde olmak üzere mukolitik amaçlı kullanımı yaygın bir ilaçtır (1). Aşırı dozda alınmaya bağlı gelişen parasetamol (asetaminofen) zehirlenmelerinde ise antidot olarak tedavide önemli bir yer tutmaktadır $(2,3)$. NAC tedavisinde uygulanması önerilen doz hastanın yaşına bağlı olarak $100-200$ $\mathrm{mg} / \mathrm{kg} / \mathrm{gün}$ arasında değişebilmektedir (4). Ancak parasetamol dışı nedenlere bağlı gelişen akut karaciğer yetmezliklerinin tedavisi için de önerilmektedir (5-7). Bunların dışında, gastrointestinal kanaldaki bezoarların tedavisi için serum fizyolojik ile seyreltilen NAC solusyonunun nazogastrik tüp yolu ile verilerek kullanımı tarif edilmiştir (8). Kistik fibrozise bağlı mekonyum ileusu gelişen çocuklarda da laparotomi sırasında bağırsağa asetil sistein uygulaması ile cerrahi rezeksiyon gereksiniminin azaldığ gösterilmiştir (9).

Akut pankreatit, akut yangisal değişiklikler sonucu ortaya çıkan ve iyileştiğinde pankreas parenkimi veya fonksiyonları üzerinde geri dönüşümlü bir süreçtir. Çoğunlukla interstisyel tutulumlu ve iyi seyirli olmakla birlikte bazen de nekrotizan tiptedir ve daha ağır seyir gösterebilmektedir. Akut pankreatitin etiyolojisinde çok çeşitli nedenlerin yanı sıra kullanılan birçok ilaç da neden olabilmektedir (10).

NAC tedavisinin akut pankreatitli hastalarda antioksidan etki sonucu pankreas asiner hücrelerindeki oksidatif hasarı azaltarak akut pankreatitin iyileşmesinde yararlı etki sağlayabileceği düşünülmektedir (11-13).

$\mathrm{Bu}$ retrospektif nitelikteki vaka serimize dayanan gözlemsel çalışmada, pankreatotoksisite sonucu geliştiği kabul edilen ve standart tedavi ile düzelme görülmemesi üzerine ebeveynlerinden alınan onam sonras1 uygulanan NAC tedavisinin ardindan iyileştikleri gözlenen ilaca bağlı akut pankreatit tanılı 6 çocuk hastamızın klinik özellikleri değerlendirilmektedir.

\section{GEREÇ VE YÖNTEM}

İlaca bağlı akut pankreatit tedavisi için uygulanan NAC tedavisi sonrası iyileşen 20072017 yılları arasında İstanbul Üniversitesi Onkoloji Enstitüsü ve Cerrahpaşa Tıp Fakültesi Hematoloji-Onkoloji Bilim Dalı ile Selçuk Üniversitesi Tıp Fakültesi Çocuk Gastroenterolojisi Bilim Dalı tarafindan izlenen 6 çocuk hastanın klinik özellikleri dosyalarındaki kayıtlı bilgileri incelenerek retrospektif olarak değerlendirildi.

Hastalarımızın tümünde akut pankreatit tanısı için "Uluslararası Çocuk Pankreatit Çalışma Grubu" tarafından önerilen tanı kriterleri (14) kullanıldı (Tablo 1).

Tablo 1: Akut pankreatit tanı kriterleri (14)

Aşağıdaki 3 kriterden en az 2'sinin bulunması;

1. Akut pankreatit ile uyumlu karın ağrısı

2. Serum amilaz ve/veya lipaz düzeylerinin normalin üst sınırına göre 3 katından daha yüksek bulunması

3. Radyolojik incelemelerde (ultrasonografi, manyetik rezonans görüntüleme veya bilgisayarlı tomografi) pankreatiti destekleyen bulguların saptanması

İlaca bağlı akut pankreatit tanısı için etiyolojide rolü olabilen tüm diğer (infeksiyöz, obstrüktif, metabolik, otoimmün, travmatik, genetik) nedenler dışlandı.

Akut pankreatitli 6 hasta pankreatitin klinik şiddetine göre NASPGHAN tarafından önerilen kriterler (15) kullanılarak sinıflandırıldı (Tablo 2).

Hastaların yıl, cinsiyet dağılımı, yaş ortalaması, yaş ortanca değeri ve yaş aralığ belirlendi. 
Tablo 2. Akut pankreatit sınıflaması (15)

\begin{tabular}{|c|c|}
\hline Sinıf & Özellikler \\
\hline Hafif & $\begin{array}{l}\text { - } \\
\text { - } \\
\text { vey sik görülen grup } \\
\text { verhangi bir organ yetersizliğine, lokal } \\
\text { - } \quad \text { Çoğunlukla } 1 \text { hafta içinde düzelme } \\
\end{array}$ \\
\hline Orta & 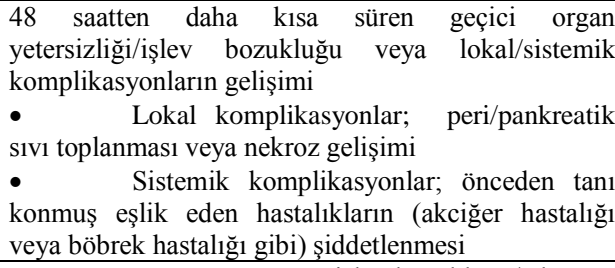 \\
\hline Ağır & $\begin{array}{l}48 \text { saatten uzun süren organ işlev bozukluğu/tek veya } \\
\text { birden fazla organda yetersizlik }\end{array}$ \\
\hline
\end{tabular}

\section{BULGULAR}

Hastalarımızın 3'ü (\% 50) kız ve 3'ü (\% 50) erkek olup yaş ortalaması $13.3 \pm 4.6$ yıl (ortanca 13.5 yıl, dağılım 8-19 yıl) idi.

Uluslararası tanı kriterlerine (14) göre 3 kriterden en az 2'sinin bulunması akut pankreatit tanısı için yeterli iken 6 hastamızın hepsinde her 3 kriter de mevcuttu.

Akut lenfoblastik lösemi (ALL) tanıl1 3 hastanın 3'ünde de polietilen glikol ile konjuge edilmiş L-asparaginaz (PEG-L-Asp ) tedavisi sonrası akut pankreatit gelişmişti. $\mathrm{Bu}$ hastalardan 1'inde cerrahi tedavi uygulanarak distal pankreatektomi yapılması gerekmişti. Cerrahi tedavi uygulanan hasta da diğer hastalar gibi herhangi bir pankreatik yetersizlik bulgusu gelişmeksizin sekelsiz ve tam olarak iyileşmişti. Bu hastada sonraki yıllarda tip 2 diyabetes mellitus yerleşti. Diğer 3 hastadan 1'inde parasetamol zehirlenmesi, 1'inde epilepsi tedavisi için kullandığg valproik asit ve 1 'inde ise ülseratif kolit tedavisinde kullanılan azathiopurine bağlı olarak akut pankreatit geliştiği düşünülmüştü.

PEG-L-Asp sonras1 akut pankreatit gelişen ALL'li 1 hastanın ultrasonografi (USG) ve bilgisayarlı karın tomografisi (BT) bulgularına göre nekrotizan tip olduğu kanısına varılırken diğer 5 hasta ise; interstisyel tutulumlu akut pankreatit olarak değerlendirilmişti. Hastaların hepsine total parenteral beslenme (TPN) verilmişti. Parasetamol zehirlenmesine bağlı interstisyel tip akut pankreatit gelişen hastanın tedavisinde TPN'ye ek olarak yalnızca NAC kullanılmıştı. İnterstisyel tip akut pankreatitli diğer 4 hasta önce TPN ve oktreotid tedavisi almış, klinik ve laboratuvar bulgularının iyileşmemesi sonrasında NAC eklenmişti. Nekrotizan tip akut pankreatitli hastanın klinik seyri çok hızlı ve şiddetli olduğundan başlangıçta NAC tedavisi almamıştı. Pankreasında psödokistler gelişen bu hastaya TPN, oktreotid ve karbapenem (imipenem/silastatin) tedavisi sonrası yanıt alınamadığından cerrahi tedavi uygulanmıştı. Cerrahi tedavi sonrası iyileşerek kemoterapisine kalındığı yerden devam edilen hastanın ALL tedavisi için gerekli olan PEGL-Asp sonrası akut pankreatite karşı NAC uygulanmıştı. Akut pankreatitin şiddeti yönünden NASPGHAN tarafindan önerilen sınıflamaya (15) göre hastalarımızın klinik özellikleri 1 hastada (nekrotizan tip) ağır derecede, diğer 5'inde ise (interstisyel tip) hafif derecede akut pankreatit ile uyumlu idi. İlaca bağlı akut pankreatit tedavisi sirasında uygulanan NAC sonrası 6 hastamızın hepsi de tam olarak iyileşmişti (Tablo 3).

\section{TARTISMA}

Çocuk yaş grubunda biliyer (kolelitiyazis, koledok kisti, safra çamuru), anatomik (pankreas divisum, annuler pankreas, safra yoları ve pankreatik kanala ait birleşim anomalileri), genetik bazı mutasyonlar, sistemik hastalıklar (sepsis, şok, Kawasaki hastalığı, hemolitik üremik sendrom), travmalar (safra yolu yaralanmas1), metabolik (hiperlipidemi, hiperkalsemi, organik asidemiler, glikojen depo hastalığı), otoimmün nedenler ve ilaçlar akut pankreatit etiyolojisinde rol alabilmektedir. Ancak ilaçlara bağlı akut pankreatitler seyrek görülmekte olup sıklığ $\quad \% \quad 0.1-2$ arasinda değişmektedir (16). 
Tablo 3. İlaca bağlı akut pankreatit gelișen 6 hastanın klinik özellikleri ve tedavileri

\begin{tabular}{|c|c|c|c|c|c|c|}
\hline $\begin{array}{l}\text { Olgu no/ } \\
\text { Yll }\end{array}$ & $\begin{array}{l}\text { Cinsiyet/Y } \\
\text { aș (yıl) }\end{array}$ & Primer tanı & $\begin{array}{l}\text { Olası etiyolojik } \\
\text { neden }\end{array}$ & Radyolojik tanı & Tedavi & Sonuç \\
\hline $1 / 2007$ & Erkek/16 & YR ALL & PEG-L-Asp & $\begin{array}{l}\text { USG: pankreasta ödematöz } \\
\text { görünüm, peripankreatik sıvı } \\
\text { BT: psödokistler, nekrotizan } \\
\text { pankreatit }\end{array}$ & $\begin{array}{l}\text { İmipenem/silastatin } \\
\text { Oktreotid } \\
\text { Distal pankreatektomi } \\
\text { NAC (diğer PEG-L-asp } \\
\text { tedavisi sonrası) }\end{array}$ & $\begin{array}{l}\text { Tam } \\
\text { iyileşme } \\
\text { (cerrahi } \\
\text { sonrasi } \\
\text { sekelsiz) }\end{array}$ \\
\hline $2 / 2007$ & $\mathrm{~K} 1 \mathrm{z} / 8$ & SR C-ALL & PEG-L-Asp & $\begin{array}{l}\text { USG: pankreasta } \text { heterojen } \\
\text { görünüm } \\
\text { BT: nekrotizan pankreatit } \\
\text { değil }\end{array}$ & $\begin{array}{l}\text { Oktreotid } \\
\text { NAC }\end{array}$ & $\begin{array}{l}\text { Tam } \\
\text { iyileşme }\end{array}$ \\
\hline $3 / 2010$ & Erkek/19 & YR B-ALL & PEG-L-Asp & $\begin{array}{l}\text { USG: pankreasta normal } \\
\text { görünüm } \\
\text { pankreatit değil) }\end{array}$ & $\begin{array}{l}\text { Oktreotid } \\
\text { NAC }\end{array}$ & $\begin{array}{l}\text { Tam } \\
\text { iyileşme }\end{array}$ \\
\hline 4/2013 & $\mathrm{K} 1 \mathrm{z} / 17$ & $\begin{array}{l}\text { Parasetamol } \\
\text { zehirlenmesi }\end{array}$ & $\begin{array}{l}\text { Yüksek doz } \\
\text { parasetamol } \\
(250 \mathrm{mg} / \mathrm{kg})\end{array}$ & $\begin{array}{l}\text { USG: pankreasta heterojen } \\
\text { görünüm } \\
\text { pankreatit değil) }\end{array}$ & NAC & $\begin{array}{l}\text { Tam } \\
\text { iyileşme }\end{array}$ \\
\hline $5 / 2017$ & Erkek/9 & Epilepsi & Valproik asit & $\begin{array}{l}\text { USG: pankreasta heterojen } \\
\text { görünüm } \\
\text { pankreatit değil) }\end{array}$ & $\begin{array}{l}\text { Oktreotid } \\
\text { NAC }\end{array}$ & $\begin{array}{l}\text { Tam } \\
\text { iyileşme }\end{array}$ \\
\hline $6 / 2017$ & $\mathrm{~K} 1 \mathrm{z} / 11$ & Ülseratif kolit & Azatiopurin & $\begin{array}{l}\text { USG: pankreasta heterojen } \\
\text { görünüm } \\
\text { MR: nekrotizan pankreatit } \\
\text { değil }\end{array}$ & $\begin{array}{l}\text { Oktreotid } \\
\text { NAC }\end{array}$ & $\begin{array}{l}\text { Tam } \\
\text { iyileşme }\end{array}$ \\
\hline
\end{tabular}

YR ALL, Yüksek riskli akut lenfoblastik lösemi; SR C-ALL, Standart riskli Common-ALL; YR B ALL, Yüksek riskli prekürsör B ALL; PEG-L-Asp, polietilen glikol ile konjuge edilmiş L-Asparaginaz; USG, karın ultrasonografisi; BT, bilgisayarlı karın tomografisi; MR, karın manyetik rezonans görüntülemesi; NAC, n-asetil sistein infüzyonu.

PEG-L-Asp, parasetamol, valproat ve azatiopurin, akut pankreatite neden olabilen ilaçlar arasında sayılmaktadır $(10,16)$. İlaca bağlı akut pankreatit olarak değerlendirdiğimiz 6 hastamızdan 3'ünde PEG-L-Asp, 1'inde yüksek doz parasetamol, 1 'inde valproat ve 1'inde ise azatiopurin kullanımı söz konusu idi.

Tedavide öncelikle tüm hastalarımızın akut pankreatit etiyolojisinde neden olabileceği düşünülen ilaç kesilerek iyileşinceye kadar kullanımına ara verilmiştir. Oral beslenme kesilerek 1 gün sonra yapilan kontrolde pankreatik enzim düzeylerinin yükselme eğiliminde olduğu görülerek total parenteral beslenme (TPN) başlanmıştır. Karın ağrısı yakınmalarının ve serum amilaz/lipaz düzeylerinin artmaya devam etmesi üzerine pankreatik sekresyonları azalttığı için akut pankreatitlerde kullanımı önerilen ve ilaca bağlı akut pankreatitlerde yararlı olduğunu destekleyen literatür bilgisine (17-20) dayanarak parasetamol zehirlenmesi dışındaki diğer 5 hastada intravenöz (IV) oktreotid infüzyon tedavisi $(1 \mu \mathrm{g} / \mathrm{kg} / \mathrm{saat}$ x 3 gün +0.5 $\mu \mathrm{g} / \mathrm{kg} / \mathrm{saat} \mathrm{x} 4$ gün) eklenmiştir.
NAC'1n çok çeşitli endikasyonlar ile birçok hastalığın tedavisinde kullanımının yararlı olduğu bilinmektedir (1-9). Parasetamol ile ilişkili veya ilişkisiz nedenlere bağl gelişen akut karaciğer hasarlarının tedavisinde rutin olarak kullanılmaktadır (2-7). Akut pankreatitli hastalarda antioksidan etki sonucu pankreas asiner hücrelerindeki oksidatif hasarı azaltarak akut pankreatitin iyileşmesinde NAC tedavisinin yararlı etki sağlayabileceği düşünülmektedir (11-13). Hastalarımıza oktreotid tedavisi başlandıktan sonraki izleyen 7 gün boyunca karın ağrısı yakınması ve pankreatik enzimlerdeki yükseklik azalmayıp artmaya devam ettiği için NAC'in akut pankreatit tedavisinde de kullanılabileceğini destekleyen literatür bilgisi $(11,12,13,21,22)$ dikkate alınarak NAC IV infüzyon (100 $\mathrm{mg} / \mathrm{kg} / \mathrm{gün}$ ) tedavisi de başlanmıştır. Parasetamol zehirlenmesine yönelik NAC başlanmış olan hastamızın tedavisine devam edilmiştir. NAC tedavisi başladığımız 5 hastamızın yakınmaları tedavi başlandıktan sonra 1 hafta içinde azalmış ve amilaz/lipaz düzeyleri de gerileyerek düzelmiştir.

NASPGHAN sinıflamasina göre hafif şiddette akut pankreatit olan hastaların 
çoğunluğunun 1 hafta içinde iyileştikleri bildirilmiştir (15). NAC tedavisi sonras1 iyileştiğini düşündügümüz 5 hastamızın NASPGHAN sınıflamasına göre hafif şiddetli akut pankreatit olgusu olmaları dikkate alındığında bu iyileşmenin NAC tedavisinden bağımsız beklenen doğal bir sonuç olması olasıdır. Ayrıca ağır derecede şiddetli nekrotizan tipte akut pankreatitli hastanın cerrahi tedaviden önce hiç NAC almaması da NAC'1n ilaca bağlı ağır akut pankreatit tedavisinde yararlı olup olmayacağ 1 yönünde fikir vermemektedir. Ancak akut pankreatit bulgularının 1 haftalık oktreotid tedavisine rağmen artarak devam etmesi üzerine başlanılan NAC tedavisi sonrası düzelmesi NAC'1n hastalarımızda yararlı olduğunu düşündürmektedir. Ayrıca, cerrahi tedavi uygulanan nekrotizan tip ağır akut pankreatitli ALL hastamız ile diğer 2 ALL'li hastamızın iyileşmelerinin ardından ara verilen kemoterapilerini yeniden aldıkları dönemlerde ortaya çıkan karın ağrısı ile pankreas enzimlerinin normalin üst sınırına göre 3 katından daha yüksek saptanmasının hemen sonrasında NAC tedavisi de uygulanmış ve ilaca bağlı gelişen yeni akut pankreatit tablolarının ortalama 1-2 gün gibi çok kısa bir sürede iyileştiği gözlenmiştir. Bu durum da ilaca bağlı akut pankreatitli olgularımızda NAC'1n antioksidan etki sonucu pankreas asiner hücrelerindeki oksidatif hasarı azaltarak yararlı etki sağlamış olabileceğini düşündürmektedir.

\section{SONUÇ}

İlaca bağlı akut pankreatitli 6 vakalık serimizin retrospektif gözlemsel sonuçlarına göre NAC, ilaca bağlı akut pankreatitte kullanılabilecek bir tedavi seçeneği gibi görünmektedir. Bu konuda geniş çaplı ve ileri düzey çalışmaların yapılması ilaca bağlı akut pankreatitli hastalarda NAC'in kullanılabilir bir tedavi seçeneği olup olamayacağının değerlendirilmesinde yarar sağlayacaktır.

\section{KAYNAKLAR}

1. Johnson K, McEvoy CE, Naqvi S, et al. Highdose oral $\mathrm{N}$-acetylcysteine fails to improve respiratory health status in patients with chronic obstructive pulmonary disease and chronic bronchitis: a randomized, placebo-controlled trial. Int J Chron Obstruct Pulmon Dis 2016;11:799-807.

2. Smilkstein MJ, Bronstein AC, Linden C, Augenstein WL, Kulig KW, Rumack BH. Acetaminophen overdose: a 48-hour intravenous Nacetylcysteine treatment protocol. Ann Emerg Med 1991;20(10):1058-63.

3. Bucaretchi F, Fernandes CB, Branco MM, et al. Acute liver failure in a term neonate after repeated paracetamol administration. Rev Paul Pediatr 2014;32(1):144-8.

4. Dart RC, Erdman AR, Olson KR, et al. Acetaminophen poisoning: An evidence-based consensus guideline for out-of-hospital management. Clin Toxicol (Phila) 2006;44(1):1-18.

5. Mumtaz K, Azam Z, Hamid S, et al. Role of Nacetylcysteine in adults with non-acetaminophen-

induced acute liver failure in a center without the facility of liver transplantation. Hepatol Int 2009; 3(4): 563-70.

6. Hu J, Zhang Q, Ren X, Sun Z, Quan Q. Efficacy and safety of acetylcysteine in "nonacetaminophen" acute liver failure: A meta-analysis of prospective clinical trials. Clin Res Hepatol Gastroenterol 2015; 39(5):594-9.

7. Saleem AF, Abbas Q, Haque AU. Use of Nacetylcysteine in children with fulminant hepatic failure caused by acuteviral hepatitis. J Coll Physicians Surg Pak. 2015; 25(5):354-8.

8. Schlang HA. Acetylcysteine in the removal of a bezoar. JAMA 1970;214(7):1329.

9. Rescola FJ, Grosfeld JL, West KJ, Vane DW. Changing patterns of treatment and survival in neonates with meconium ileus. Arch Surg 1989;124(7):837-40.

10. Lowe ME. Pancreatitis. In: Wyllie R, Hyams JS, Kay M, eds. 5th ed. Pediatric Gastrointestinal and Liver Disease. Philadelphia: Elsevier; 2016. p.1016-26.

11. Sevillano S, De la Mano AM, De Dios I, Ramudo L, Manso MA. Major pathological mechanisms of acute pancreatitis are prevented by $\mathrm{N}$-acetylcysteine. Digestion 2003;68(1):34-40.

12. Sevillano S, De Dios I, De la Mano AM, Manso MA. N-acetylcysteine induces beneficial changes in the acinar cell cycle progression in the course of acute pancreatitis. Cell Prolif 2003;36(5):279-89.

13. Sateesh J, Bhardwaj P, Singh N, Saraya A. Effect of antioxidant therapy on hospital stay and complications in patients with early acute pancreatitis: a randomised controlled trial. Trop Gastroenterol 2009;30(4):201-6.

14. Morinville VD, Husain SZ, Bai $\mathrm{H}$, et al. Definitions of pediatric pancreatitis and survey of current clinical practices: report from Insppire (International Study Group Of Pediatric Pancreatitis: In Search For A Cure). J Pediatr Gastroenterol Nutr 2012; 55(3): 261-5.

15. Abu-El-Haija M, Kumar S, Szabo F, Werlin S, Conwell D, Banks $\mathrm{P}$, et al. Classification of acute pancreatits in the pediatric population: Clinical report 
from the NASPGHAN pancreas committee. J Pediatr Gastroenterol Nutr 2017;64(6): 984-990

16. Badalov N, Baradarian R, Kadirawel I, et al. Drug-induced acute pancreatitis: an evidence-based review. Clin Gastroenterol Hepatol 2007; 5(6): 648-61.

17. Wu SF, Chen AC, Peng CT, Wu KH. Octreotide therapy in asparaginase-associated pancreatitis in childhood acute lymphoblastic leukemia. Pediatr Blood Cancer 2008; 51(6): 824-5.

18. Suzuki M, Takata O, Sakaguchi S, Fujimura J, Saito M, Shimizu T. Retherapy using L-asparaginase with octreotide in a patient recovering from Lasparaginase-induced pancreatitis. Exp Hematol 2008; 36(3): 253-4.

19. Suzuki M, Sai JK, Shimizu T. Acute pancreatitis in children and adolescents. World $\mathbf{J}$ Gastrointest Pathophysiol 2014; 5(4): 416-26

20. Wang R, Yang F, Wu H, et al. High-dose versus low-dose octreotide in the treatment of acute pancreatitis: a randomized controlled trial. Peptides 2013; 40: 57-64.

21. Mumcu S, Alhan E, Türkyilmaz S, Kural BV, Erçin C, Kalyoncu NI. Effects of N-acetylcysteine on acute necrotizing pancreatitis in rats. Eur Surg Res 2005; 37(3): 173-8.

22. Eşrefoğlu M, Gül M, Ates B, Batçioğlu K, Selimoğlu MA. Antioxidative effect of melatonin, ascorbic acid and $\mathrm{N}$-acetylcysteine on caeruleininduced pancreatitis and associated liver injury in rats. World J Gastroenterol 2006;12(2): 259-64. 